\title{
Editorial
}

\section{Surgical-Site Infections After Coronary Artery Bypass Graft Surgery: Discriminating Site-Specific Risk Factors to Improve Prevention Efforts}

\author{
Marie-Claude Roy, MD, MSc
}

The story of the surgical treatment of cardiac lesions, either traumatic, congenital, degenerative, or postinfective, is almost entirely a 20th-century story. Experimental cardiac surgery began more than 100 years ago with M.H. Block, a German surgeon, who published a report on wounds of the heart in 1882, in which he described suture of rabbit hearts. $\mathrm{He}$ strongly urged that the procedure be used in man. ${ }^{1} \mathrm{At}$ that time, Billroth is reported to have said: "A surgeon who would attempt such an operation should lose the respect of his colleagues." 1 Nevertheless, in 1896, Ludwig Rehn of Frankfort became the first surgeon to suture a human heart laceration successfully, thus inaugurating the era of cardiac surgery. ${ }^{1}$ Nowadays, with an estimated 468,000 coronary artery bypass grafts (CABGs) performed each year in the United States, ${ }^{2}$ cardiac surgery has become the "epitome of contemporary high-technology medical care."3

Approximately $2 \%$ to $20 \%$ of CABGs are complicated by a surgical-site infection (SSI). 4,5 Much of the literature on SSI following cardiothoracic surgical procedures focus on deep chest infections, which, although not frequent (complicating $0.5 \%$ to $5 \%$ of cardiac procedures 4,5 ), are important because of the high morbidity, mortality, and immense costs they add to the healthcare system.

Host, surgical, and microbiological risk factors are intertwined in a complex way for an SSI to develop. Extremes of age, prolonged preoperative stay, remote infection, and duration of surgery are some of the risk factors that have been associated consistently with SSI. 6

For patients undergoing cardiac surgery, the median sternotomy and the extracorporeal circulation both cause considerably greater stress on the host defenses than general surgical procedures. $3,7,8$

\section{RISK FACTORS FOR SURGICAL-SITE INFECTION OF THE STERNAL WOUND}

Surgical-site infection of the sternal wound includes superficial SSI, deep sternal SSI, sternal osteomyelitis, mediastinitis, and endocarditis. These often have been pooled together in the analysis of risk factors. Host intrinsic risk factors that have been linked specifically to SSI of the sternal wound include obesity, ${ }^{4,9-11}$ diabetes mellitus, ${ }^{4,9-}$ 13 current cigarette smoking, 9 and steroid therapy, 13 the former two risk factors being the most frequently reported (Table 1). Kluytmans and colleagues further demonstrated that the risk of developing SSI was higher in the diabetic patient using insulin therapy than in the diabetic patient treated with oral agents. 12 These authors also showed that preoperative nasal carriage of Staphylococcus aureus by patients was an independent risk factor for $S$ aureus sternal-wound infections. ${ }^{12}$ A randomized clinical trial has yet to prove

From the Division of Microbiology, Centre Hospitalier Affilié Universitaire de Québec, Quebec City, Quebec, Canada. Address reprint requests to Marie-Claude Roy, MD, MSc, Division of Microbiology, Centre Hospitalier Affilié Universitaire de Québec, Pavillon Enfant-Jésus, 1401-18e Rue, Quebec City, Quebec G1J 1Z4, Canada.

97-ED-204. Roy M-C. Surgical-site infections after coronary artery bypass graft surgery: discriminating site-specific risk factors to improve prevention efforts. Infect Control Hosp Epidemiol 1998;19:229-233. 
TABLE 1

Risk Factors for Surgical-Site Infection at the STERNAL SITE

\begin{tabular}{|c|c|}
\hline \multicolumn{2}{|l|}{ Host Intrinsic } \\
\hline Female gender 10,35 & Prolonged perfusion time ${ }^{15}$ \\
\hline Male gender 36 & Duration of surgery $4,11,15$ \\
\hline Increasing age $\mathrm{e}^{4,35}$ & $\begin{array}{l}\text { Use of intraaortic balloon } \\
\text { pump } 38\end{array}$ \\
\hline Obesity $9-11,24,35$ & Postoperative bleeding 14,15 \\
\hline Cigarette smoking 9 & Reoperation $11,14,15$ \\
\hline $\mathrm{COPD}^{36}$ & Sternal rewiring ${ }^{14}$ \\
\hline Poor functional cardiac status 4 & Use of IMA in $\mathrm{CABG}^{11,21}$ \\
\hline $\begin{array}{l}\text { Prolonged ventilation } \\
\quad \text { support } 19,35,37\end{array}$ & Type of bone saw used 16,17 \\
\hline \multicolumn{2}{|c|}{$\begin{array}{l}\text { Low cardiac output state }{ }^{15,19,37} \text { Indiscriminate use of } \\
\text { electrocautery } 39\end{array}$} \\
\hline Diabetes mellitus $9-13,24$ & Shaving methods 25,40 \\
\hline Steroid therapy 13 & Use of bone wax 41 \\
\hline \multicolumn{2}{|l|}{$\begin{array}{l}\text { Staphylococcus aureus } \\
\text { nasal carriage } \mathrm{e}^{12}\end{array}$} \\
\hline Preoperative length of stay $>5 \mathrm{~d}$ & \\
\hline
\end{tabular}

Abbreviations: $\mathrm{CABG}$, coronary artery bypass graft; $\mathrm{COPD}$, chronic obstructive pulmonary disease; IMA, internal mammary artery.

this assumption.

Surgical risk factors linked with SSI at the sternal site are numerous. Previous sternotomy, $11,14,15$ complexity of surgery, type of bone saw used, 16,17 type of sternal closure, ${ }^{17}$ use of bone wax, blood transfusions, 14 and early reexploration to control hemorrhage $11,14,15,18$ are examples of these (Table 1).

According to some experts, harvesting the internal mammary artery (IMA) is a risk factor for SSI at the sternal site. It is logical to think that the significant sternal ischemia produced by harvesting one or two IMAs predisposes patients to sternal osteomyelitis and mediastinitis; yet, most opinions seem to merge toward the conclusion that single IMA grafting does not appear to increase the risk of sternal-wound infection. ${ }^{11,19}$ Furthermore, because of the much higher patency rate of the IMA when compared to the saphenous vein (90\% of IMAs are still patent 10 years after CABG vs $50 \%$ for the saphenous vein), using the IMA has become the standard of care whenever this is possible. ${ }^{20}$ Using both IMAs remains controversial in regard to the development of SSI. Kouchoukos and colleagues found an increased risk of SSI at the sternal site from bilateral IMAs in patients with obesity, diabetes, or prolonged mechanical ventilation. ${ }^{21}$ Therefore, other risk factors may have to be present for this risk factor to be realized.

\section{RISK FACTORS FOR SAPHENOUS VEIN HARVEST-SITE INFECTIONS}

The most common infections developing after CABGs are saphenous vein harvest-site infections (HSIs), which complicate $2 \%$ to $13 \%$ of all CABGs. Because these infections often are perceived as somewhat trivial by the surgical team, and because the associated mortality is so low, HSIs probably are underreported in many published studies. Moreover, the surveillance programs in some institutions may not be sensitive enough to give accurate HSI rates; yet, HSIs equally contribute to excess length of stay, readmissions, and increased cost. 22,23

In this issue of Infection Control and Hospital Epidemiology, Vuorisalo and colleagues analyzed risk factors for SSI among a population of 884 patients who underwent $\mathrm{CABG}$ without valve procedures. ${ }^{24}$ By excluding valve procedures, the authors avoided one caveat of many previous studies: pooling different patient populations who may have too many different risk features. Some investigators have published a higher incidence of sternal infections after CABGs than with other open heart procedures and speculated that this was due to contamination from the donor-vein site. ${ }^{9}$

Harvest-site infections and sternal infections need not be studied in a combined manner, for their pathogenesis and microbiology are quite different. Vuorisalo and colleagues are among the few investigators who analyzed risk factors for HSI specifically. 24 The high infection rate found in their analysis (19.5\%) mostly reflected the HSI rate (15.4\%). Active surveillance certainly increased the sensitivity of their case-finding methods for HSI; yet, using antibiotic prescription as a surrogate marker for postdischarge SSI lacks specificity and may have introduced misclassification bias in their analysis. Indeed, the authors underlined the late wound complications often misdiagnosed as SSI upon discharge and the tendency to overtreat simple delay in wound healing with antibiotic. Nevertheless, despite their methodology difficulties, the authors did include postdischarge surveillance in their analysis.

Consistent with previous reports, Vuorisalo and colleagues found that diabetes and obesity (as delineated by body mass index) were major risk factors for SSI at the sternal site. ${ }^{24}$ In contrast, the only risk factor independently associated with HSI was female gender $(P=.003)$. Delaria and colleagues also found that women were at significantly higher risk than controls of any leg-wound complication (infection, wound separation, or hematoma) after undergoing CABG (Table 2). ${ }^{2} 3$ 


\section{PREVENTIVE MEASURES}

Once risk factors are identified, one must ask if they can be modified. Most host intrinsic risk factors are not easy to change (eg, age, gender), whereas others are, but lack good scientific evidence that modification would reduce SSI rates (eg, losing weight for obese patients or stopping cigarette smoking before surgery). Vuorisalo and colleagues suggest hypotheses to take their results further in regard to preventive strategies. 24 For example, because female gender is the only independent risk factor associated with HSI, the authors suggest that women cease shaving their legs prior to elective $\mathrm{CABG}$, as this practice may explain the higher HSI rate in women than men.

Preoperative preparation of the patient deserves meticulous attention. Optimizing the nutritional state of patients, eradicating foci of low-grade infections (especially of dental, respiratory, and genitourinary origin), antiseptic showers before surgery, and eliminating routine chest-hair shaving are examples of requisite preoperative adjuncts.

Surgical risk factors are more easy to change than host risk factors. Investigation of numerous outbreaks have undercovered violations of infection control standards in the operating room. In Slaughter's study, breaks in techniques in the operating room and the fact that nonexperienced residents were harvesting the saphenous vein were thought to be important factors to explain the increase in HSI rates. ${ }^{13}$ The authors underlined that the leg and chest wounds should be considered as separate fields, that instruments should not be shared by surgeons operating on those two fields, and that personnel should change gloves when moving from one field to the other. After implementing those changes in the operating room and after hiring two physician's assistants specifically to harvest veins, the leg infection rates decreased. 13

The polymicrobial nature of HSI with a preponderance of Enterobacteriaceae may warrant longer leg-skin antibacterial scrub or perhaps gastrointestinal decontamination. ${ }^{25}$ In contrast, if $S$ aureus predominates in an institution, applying mupirocin to the patients' nares preoperatively may be a plausible intervention to reduce SSI rates.

\section{ANTIMICROBIAL PROPHYLAXIS IN CARDIAC SURGERY}

The rational use of perioperative antibiotic prophylaxis in cardiac surgery has proven to be efficacious in reducing SSI rates 26,27 and is one of the most important steps in preparing a patient for surgery.

In a second article in this issue, Vuorisalo and
TABLE 2

Risk Factors for Saphenous Vein Harvest-Site INFECTIONS

\begin{tabular}{lc}
\hline Risk Factor & Reference \\
\hline Female gender & 23,24 \\
Obesity & 13,23 \\
Staphylococcus aureus nasal carriage & 42 \\
\hline
\end{tabular}

colleagues, studying the same population, tried to demonstrate that vancomycin was not superior to cefuroxime for prophylaxis in patients undergoing CABG. ${ }^{28}$ Their randomized clinical trial showed the same infection rates in both arms of the study: a $3.5 \%$ SSI rate in the vancomycin group $(n=440$ patients) vs a $3.2 \%$ SSI rate in the cefuroxime group $(n=444)$. Therefore, the authors concluded that cephalosporins are favored for prophylaxis before $\mathrm{CABG}$, as these drugs are cheaper and easier to administer than vancomycin. Furthermore, the authors underlined the overuse of vancomycin linked to the vancomycin-resistant Enterococcus problem, which has plagued many hospitals in the past few years.

Some caveats have to be underlined before reaching these conclusions. First, having too few patients in each arm of the study population may have precluded a statistically significant difference between the two drugs. In contrast with Vuorisalo's study, at least two articles showed that vancomycin was superior to cephalosporins for prophylaxis in CABG. Maki and colleagues showed that vancomycin was associated with a statistically significant reduced rate of SSI when compared to cefazolin and cefamandole $(P=.05)^{29}$; the mean length of stay after surgery also was lowest in the vancomycin group $(P<.01)$. Nafziger and colleagues, in a preliminary report, reached similar conclusions: prophylaxis with a firstgeneration cephalosporin appeared to be a risk factor for mediastinitis when compared to vancomycin (OR, 4.5). Logistic regression showed that the bestfitting model in this case-control study included diabetes and type of antimicrobial prophylaxis $(P<.001) .30$ We need more evidence to show that cephalosporins are at least as good as vancomycin for CABG prophylaxis before withdrawing the latter antibiotic for this purpose in response to the threat of vancomycin-resistant enterococci. Furthermore, if methicillin-resistant $S$ aureus (MRSA) or methicillinresistant Staphylococcus epidermidis are major causes of SSI in an institution, one must consider vancomycin as prophylaxis.

In analyzing prophylaxis, one also must con- 
sider timely administration of the drug, as this variable is of utmost importance in having good tissue levels of the drug when the surgeon performs the incision. ${ }^{31}$ Vuorisalo and colleagues mention that all drugs were given at induction of anesthesia, but did not detail further. ${ }^{28}$ We have shown in a preliminary report that prescribing an antibiotic at induction of anesthesia does not ensure necessarily that the drug is given on the proper timing before incision. ${ }^{32}$ Among 204 patients who received either cefazolin or cefoxitin as prophylaxis for surgery, 35\% did not receive the drug on time, of whom $22 \%$ received it too early ( $>2$ hours before incision) and $8 \%$ received it after the surgeon performed the incision, thus precluding proper concentration of the antibiotic in tissues. Yet, all antibiotics were prescribed at induction of anesthesia. 32

Furthermore, to achieve high tissue levels throughout the surgical procedure, one must give an optimal dose of the drugs. Although Vuorisalo and colleagues delineated that obesity might explain inappropriate concentrations of antibiotic in tissues, they still prescribed suboptimal doses of antibiotic (750 $\mathrm{mg}$ for postoperative doses of cefuroxime and $1 \mathrm{~g}$ of vancomycin) 28 ; yet, $24 \%$ of their study population was considered obese. Higher doses of cephalosporins should be used for patients who weigh $>80 \mathrm{~kg}$ (eg, 2 $\mathrm{g}$ of cefazolin instead of $1 \mathrm{~g}$ ), 33 and this full dose should be repeated intraoperatively if the procedure extends beyond 3 hours. For vancomycin, at least 15 $\mathrm{mg} / \mathrm{kg}$ should be administered preoperatively (provided that the patient does not have renal insufficiency), particularly because this drug adheres to the bypass apparatus. ${ }^{34}$ Because postoperative doses are unnecessary for most surgical procedures (including $\mathrm{CABG}$ ), the total dose for the day is not excessive, and high tissue levels of antimicrobial are achieved while the wound is open, which is clearly what matters in surgical prophylaxis.

Therefore, clinical trials on antimicrobial prophylaxis should address not only the choice of the drug but also other important variables which, when properly controlled, reduce SSI rates: timely administration of the antibiotic before incision; the need to repeat intraoperative doses when the surgical procedure is long; giving appropriate full doses, particularly when the patient is obese; and the particular pharmacokinetics of the antibiotic, such as its removal by the extracorporeal circulation during $\mathrm{CABG}$.

\section{CONCLUSION}

Over the last decade, prevention of SSI after cardiac surgery has become an important component of quality assurance and hospital cost containment; yet, with the amalgam of studies published, it is hard to delineate which risk factors for SSI are most important and where infection control practitioners and surgeons can intervene. To answer these questions, one must interpret the results of these studies with caution and compare what truly can be compared.

The potential differences in patient populations, the reliability of criteria used for the diagnosis of SSI, the sensitivity of the surveillance methods and whether or not postdischarge surveillance was performed, the many different variables and endpoints included, the study design (most often case-control designs), the choice and timely administration of antimicrobial agents for prophylaxis, the types of procedures, and the use of one or both IMAs as graft all make results among studies difficult to compare.

In this era of attention to quality heath care, many authorities have turned to surveillance of CABGs and cardiac catheterizations to evaluate and compare hospital performance. Hence, it will be increasingly relevant to compare the same populations, the same endpoints, and the same procedures before reaching conclusions on one's performance.

\section{REFERENCES}

1. Brieger GH. The development of surgery: historical aspects important in the origin and development of modern surgical science. In: Sabiston, ed. Textbook of Surgery. Philadelphia, PA: W.B. Saunders; 1977:1-26.

2. American Heart Association. Heart and Stroke Facts. 1995 Statistical Supplement; 1995.

3. Kaiser A. Risk factors for infection in cardiac surgery: will the real culprit please stand up? Infect Control 1984;5:369-370.

4. Simchen E, Shapiro M, Marin G, Sacks T, Michel J. Risk factors for post-operative wound infection in cardiac surgery patients. Infect Control 1983;4:215-220.

5. Walker WS, Faichney A, Raychaudhury T, Prescott RJ, Calders MA, Sang CTM, et al. Wound prophylaxis in thoracic surgery. Thorax 1984;39:121.

6. Mayhall CG. Surgical infections including burns. In: Wenzel RP, ed. Prevention and Control of Nosocomial Infections. Baltimore, MD: Williams \& Wilkins; 1993:614-664.

7. Parker DJ, Cantrell JW, Karp RB, Stroud RM, Digerness SB. Changes in serum complement and immunoglobulins following cardiopulmonary bypass. Surgery 1972;71:824-827.

8. Silva J, Hoeksema H, Fekety F. Transient defects in phagocytic functions during cardiopulmonary bypass. J Thorac Cardiovasc Surg 1974;67:175-183.

9. Nagachinta T, Stephens M, Reitz B, Polk B. Risk factors for surgical-wound infection following cardiac surgery. J Infect Dis 1987;156:967-973.

10. Lilienfeld D, Vlahov D, Tenney J, McLaughlin J. Obesity and diabetes as risk factors for postoperative wound infections after cardiac surgery. Am J Infect Control 1988;16:3-6.

11. Loop FD, Lytle BW, Cosgrove DM, Mahfood S, McHenry MC, Goormastic M, et al. Sternal wound complications after isolated coronary artery bypass grafting: early and late mortality, morbidity, and cost of care. Ann Thorac Surg 1990;49:179-187.

12. Kluytmans J, Mouton J, Ijzerman E, Vandenbroucke-Grauls C, Maat A, Wagenvoort J, et al. Nasal carriage of Staphylococcus aureus as a major risk factor for wound infections after cardiac surgery. J Infect Dis 1995;171:216-219.

13. Slaughter M, Olson M, Lee J, Ward H. A fifteen-year wound 
surveillance study after coronary artery bypass. Ann Thorac Surg 1993;56:1063-1068.

14. Ottino G, De Paulis R, Pansini S, Rocca G, Tallone MV, Comoglio C, et al. Major sternal wound infection after openheart surgery: a multivariate analysis of risk factors in 2,579 operative procedures. Ann Thorac Surg 1987;44:173-179.

15. Culliford AT, Cunningham JN, Zeff RH, Isom OW, Teiko P, Spencer FC. Sternal and costochondral infections following open-heart surgery: a review of 2,594 cases. J Thorac Cardiovasc Surg 1976;72:714-725.

16. Hehrlein F, Herrman H, Kraus J. Complications of median sternotomy in cardiovascular surgery. J Thorac Cardiovasc Surg 1972;13:390.

17. Nelson J, Nelson R. The incidence of hospital wound infections in thoracotomies. J Thorac Cardiovasc Surg 1967;54:586.

18. Engelman RM, Williams CD, Gouge TH, Chase RM, Falk EA, Boyd $\mathrm{AD}$, et al. Mediastinitis following open heart surgery: review of two years' experience. Arch Surg 1973;107:772-778.

19. Grossi EA, Culliford AT, Krieger KH, Kloth D, Press R, Baumann G, et al. A survey of 77 major infectious complications of median sternotomy: a review of 7,949 consecutive operative procedures. Ann Thorac Surg 1985;40:214-223.

20. Nwasokwa ON. Coronary artery bypass graft disease. Ann Intern Med 1995;123:528-545.

21. Kouchoukos N, Wareing T, Murphy S, Pelate C, Marshall W. Risks of bilateral internal mammary artery bypass grafting. Ann Thorac Surg 1990;49:210-219.

22. Roy M-C, Herwaldt LA, Embrey R, Kuhns K, Wenzel RP, Perl TM. A 3-year wound surveillance study in cardiothoracic surgery. Presented at the Thirty-fourth Interscience Conference on Antimicrobial Agents and Chemotherapy; 1994; Orlando, FL.

23. DeLaria G, Hunter J, Goldin M, Serry C, Javid H, Najafi H. Leg wound complications associated with coronary revascularization. J Thorac Cardiovasc Surg 1981;81:403-407.

24. Vuorisalo S, Haukipuro K, Pokela R, Syrjälä H. Risk features for surgical site infections in coronary artery bypass surgery. Infect Control Hosp Epidemiol 1998;19:240-247.

25. L'Ecuyer PB, Murphy D, Little JR, Fraser VJ. The epidemiology of chest and leg wound infections following cardiothoracic surgery. Clin Infect Dis 1996;22:424-429.

26. Myerowitz P, Caswell K, Lindsay W, Nicoloff D. Antibiotic prophylaxis for open-heart surgery. J Thorac Cardiovasc Surg 1977;73:625

27. Fong IW, Baker CB, McKee DC. The value of prophylactic antibiotics in aorta-coronary bypass operations. J Thorac Cardiovasc Surg 1979;78:908-913.

28. Vuorisalo S, Pokela R, Syrjälä H. Comparison of vancomycin and cefuroxime for infection prophylaxis in coronary artery bypass surgery. Infect Control Hosp Epidemiol 1998;19:234-239.

29. Maki DG, Bohn MJ, Stolz SM, Kroncke GM, Acher CW, Myerowitz PD. Comparative study of cefazolin, cefamandole, and vancomycin for surgical prophylaxis in cardiac and vascular operations. J Thorac Cardiovasc Surg 1992;104:1423-1434.
30. Nafziger DA, Perl TM, Herwaldt LA, Kuhns KR, Hollis RJ, Wenzel RP. Mediastinitis at a tertiary referral hospital. Presented at the Thirty-third Interscience Conference on Antimicrobial Agents and Chemotherapy; October 1992; Anaheim, CA.

31. Classen DC, Evans RS, Pestotnik SL, Horn SD, Menlove RL, Burke JP. The timing of administration of antibiotics and the risk of surgical-wound infection. N Engl J Med 1992;326: 281-286.

32. Roy M-C, Gagné E, Paradis A, Gourdeau M. Antimicrobial prophylaxis in surgery: Evaluation of practices in a tertiary care hospital. Presented at the Thirty-seventh Interscience Conference on Antimicrobial Agents and Chemotherapy; September 1997; Toronto, Ontario, Canada.

33. Wurtz R, Itokazu G, Rodvold K. Antimicrobial dosing in obese patients. Clin Infect Dis 1997;25:112-118.

34. Farber BF, Karchmer AW, Buckley MJ, Moellering RC. Vancomycin prophylaxis in cardiac operations: determination of an optimal dosage regimen. J Thorac Cardiovasc Surg 1983;85:933-940.

35. Breyer RH, Mills SA, Hudspeth AS, Johnston FR, Cordell AR. A prospective study of sternal wound complications. Ann Thorac Surg 1984;37:412.

36. Demmy TL, Park SB, Liebler GA, Burkholder JA, Maher TD, Benckart DH, et al. Recent experience with major sternal wound complications. Ann Thorac Surg 1990;49:458-462.

37. Rutledge R, Applebaum R, Kim N. Mediastinal infection after open heart surgery. Surgery 1985;97:88-92.

38. Hazelrigg SR, Wellons HA, Schneider JA, Kolm P. Wound complications after median sternotomy: relationship to internal mammary grafting. J Thorac Cardiovasc Surg 1989;98: 1096-1099.

39. Nishida H, Grooters RK, Soltanzadeh H, Thielman KC, Schneider RF, Kim W-P. Discriminate use of electrocautery on the median sternotomy. J Thorac Cardiovasc Surg 1991;101: 488-494.

40. Ko W, Lazenby DW, Zelano JA, Isom OW, Krieger KH. Effects of shaving methods and intraoperative irrigation on suppurative mediastinitis after bypass operations. Ann Thorac Surg 1992;53:301-305.

41. Nelson DR, Buxton TB, Luu QN, Rissing JP. The promotional effect of bone wax on experimental Staphylococcus aureus osteomyelitis. J Thorac Cardiovasc Surg 1990;99:977-980.

42. Morales E, Herwaldt LA, Nettleman MD, Larson C, Sanford L, Perl TM. Staphylococcus aureus carriage and saphenous vein harvest site infection following coronary artery bypass surgery. Presented at the Thirty-fourth Interscience Conference on Antimicrobial Agents and Chemotherapy; October 1994; Orlando, FL. 